\title{
Pedagogical Conditions Necessary for Training Teachers to Manage the Development of Intellectually Gifted Students
}

\author{
G. R. Eremeeva \\ Institute of International Relations, History and Oriental \\ Studies \\ Kazan Federal University \\ Kazan, Russia \\ guzeliksanova@rambler.ru
}

\author{
R. R. Bikbulatov \\ Nazarbaev Intellectual School of Physics and \\ Mathematics \\ Kostanai, Kazakhstan \\ ruslan97129@mail.ru
}

\author{
A. R. Baranova \\ Institute of International Relations, History and Oriental Studies \\ Kazan Federal University \\ Kazan, Russia \\ baranova.alfiyarafailovna@mail.ru
}

\begin{abstract}
The problem relevance under study is caused by need of developing the teachers who work with intellectually gifted students in the conditions of continuing professional education. The purpose of the article is to reveal pedagogical conditions, connected with inclusion of teachers in an enriched creative and research environment, their self-development and providing them with psychological support. The results showed efficiency of using these pedagogical conditions for teachers' readiness formation to manage the development of intellectually gifted students. Person-oriented and constructivist approaches are the leading in research of this problem. The article may be useful in the teaching process in institutions of continuing professional education and giving lectures on psychology and pedagogy in educational institutions, where intellectually gifted students are taught.
\end{abstract}

Keywords - student; teaching; education; teacher; learning; development; intellectually gifted.

\section{INTRODUCTION}

In the modern, rapidly changing and high-tech world, there is an increasing interest in realization of intellectual and creative potential of a man as one of the main resources of the development of society. In this regard, the issue of the training competitive, creative specialists capable of critical thinking, mobility, non-standard solutions of professional problems becomes relevant. This actualizes a set of problems related to the development of intellectually gifted students.

At present, certain theoretical and experimental material is accumulated on this issue. However such systematic work is conducted generally at a school level, whereas in institutions of higher education and vocational schools it is carried out insufficiently. It is confirmed by the results of a number of researches, where it is noted that training of teachers in this direction is most often unsystematic, focused on the development of subject competences (N.V. Kolodiy [1], V.I. Panov [2], A.K. Satova [3], G.R. Eremeeva [4] and others). Analysis of educational programs of pedagogical institutions of higher education proves this conclusion. In particular, in pedagogical institutions of higher education, there are no courses among obligatory disciplines aimed at training future specialists to the management of the development of intellectually gifted students. This direction is represented in the catalogs of elective disciplines by single courses, namely "Solution of Olympiad tasks", "Psychology of endowments", "Methodology of work with gifted children", etc. And these disciplines are not chosen by all students at the undergraduate level. In this regard, future teachers do not have the competencies necessary for the development of intellectually gifted students.

The issue of professional preparation of teachers has always been important in pedagogy and psychology. A significant contribution to its development was made by studies on the structure of professional activity (N.V. Kuzmina [5], V.A. Slastenin [6] and others), on improvement of quality of pedagogical education (Ye.N. Shiyanov [7], Ye.V. Yakovlev [8] and others). To date, a number of studies have been devoted to the formation of psychological readiness of future teachers to work with gifted schoolchildren (N.V. Dudyreva [9], Ye.L. Melnikova [10], I.I. Ushatikova [11] and others).

In the system of higher education, it is not always possible to train a specialist capable of managing the development of intellectually gifted students. The relevance of this research is that the authors suggest carrying out this process in the conditions of continuing professional education. A teacher is not always ready for a management activity and the readiness itself has no systematic character of this activity, as well as in teaching there are no purposes focused on developing personality of an intellectually gifted student. Successful work requires the implementation of various pedagogical conditions.

\section{METHODS AND MATERIALS}

For training the teachers to manage the development of intellectually gifted students, let us suggest using 
constructivist, person-oriented approaches in education. Methods of update, selection, analysis, systematization and generalization of original facts and sources, applied in the research, promoted studying of teachers' training continuing professional education. Methods of statistical analysis proved the efficiency of the pedagogical conditions studied in this research.

In conditions of continuing professional education, it is possible to provide the innovative nature of formation of teachers' readiness to manage the development of intellectually gifted students, using educational programs aimed at various target groups.

In this research, the authors will adhere to the point of view of Ye.V. Berezhnova [12] which specifies that a condition is the circumstance under which this or that effective action is possible.

Due to pedagogical conditions, subjectivity must be considered from a position of methodological approaches, change of concepts of education and research skills. That is, considering objective circumstances, the conditions have to carry a novel aspect.

Pedagogical conditions are understood as a set of measures created in the educational process of continuing professional education, which have to provide teachers with achievement of the necessary level of readiness to manage the development of intellectually gifted students.

\section{RESULTS}

An important moment in the development of such specialist is the creation of a set of pedagogical conditions, which include:

1) activation of teachers' innovative activity by means of their inclusion in an enriched creative and research environment in the process of mastering continuing educational programs;

2) stimulation of teachers' professional and personal selfdevelopment through technologies based on person-oriented teaching;

3) provision of psychological support for the formation of teachers' readiness to manage the development of intellectually gifted students.

These conditions are objective, but they are characterized by a subjective orientation as well.

Each of the proposed pedagogical conditions serves as the formation of readiness to manage the development of intellectually gifted students (Fig. 1).

\section{DISCUSSION}

The first pedagogical condition - activation of teachers' innovative activity by means of their inclusion in an enriched creative and research environment in the process of mastering continuing educational programs - is represented by the fact that work with intellectually gifted students requires a multidisciplinary teacher with an interest in professional activity.

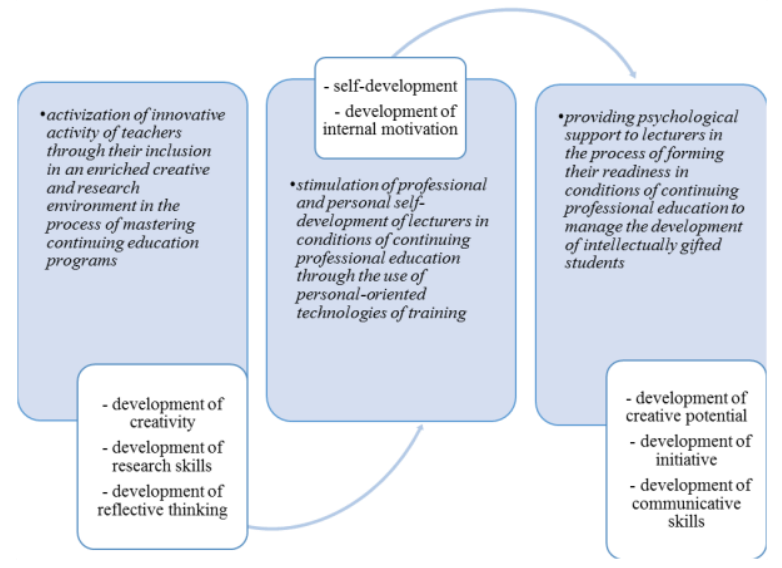

Fig.1 Realization of pedagogical conditions

The teachers' task is to carry out creative activity and find independently ways to solve appeared problems. In the process of training teachers in the conditions of continuing professional education, it is necessary to organize such kind of activity in which a teacher would be able to have and develop creativity.

Since the authors offer teachers to be included in an enriched creative and research environment, they need to know problematic of the issue under study, be able to test theoretical principles, develop creativity and research skills. Enrichment of the creative and research environment is carried out due to the special course "Psychological and pedagogical training of teachers to manage the development of intellectually gifted students", different trainings, etc. Problem and interactive methods allow enriching the technological component of this environment (Fig. 2).

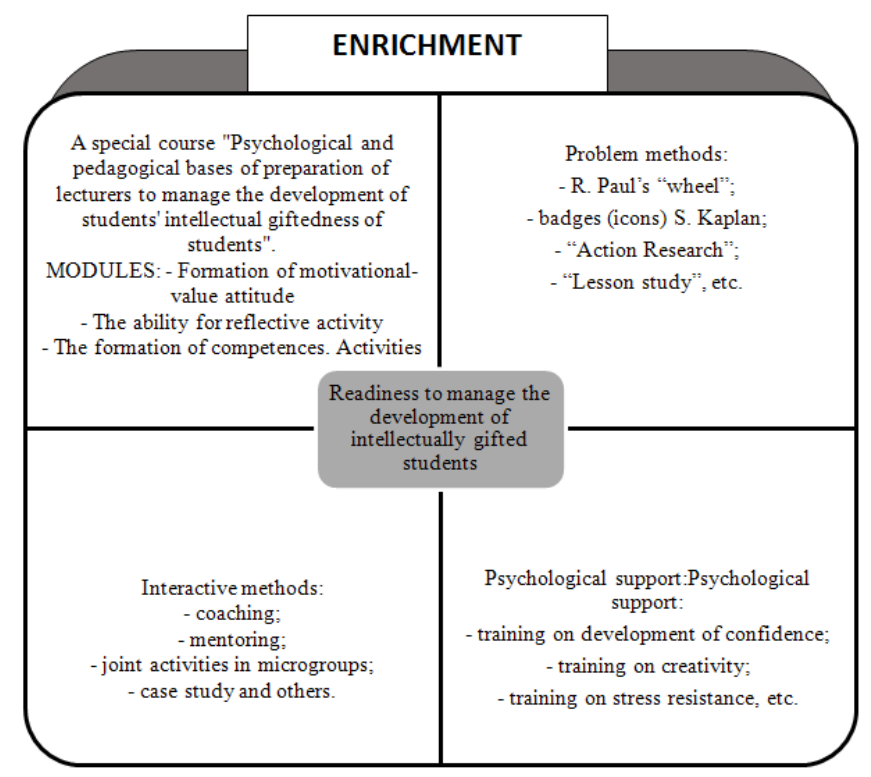

Fig. 2. Teacher's inclusion in an enriched creative and research environment 
The proposed environment is dynamic. That is a teacher, when using problem-based training of intellectually gifted students, needs to develop some skills, namely, to learn to define a problem; to do an analysis of all options of the solution of this problem; to estimate the efficiency of each option; to propose solutions.

To develop teacher's research activity, it is necessary to create certain conditions. These conditions, in this study, are the conditions of continuing professional education. A teacher should be trained to conduct researches and on their basis to make certain conclusions on the organization or updating one's own activities. Attending the courses he has to be involved in situational activities.

The second pedagogical condition - stimulation of teachers' professional and personal self-development in the conditions of continuing professional education through the usage of person-oriented teaching technologies - was proposed by the authors in connection with the fact that teachers' work with intellectually gifted students requires continuous professional growth. A teacher has to be personally oriented to work with this category of students; values have to be developed which will lead subsequently to setting goals. For this purpose a teacher needs to develop oneself and should develop one's professional skills, should constantly determine oneself and work out one's own strategies for professional growth.

In the authors' opinion, self-development is a process that is directed to achieve the set goals and improve the existing potential of the personality (Fig. 3).

A teacher working with intellectually gifted students has to develop using person-oriented teaching technologies. The authors adhere to the point of view of I.S. Yakimanskaya [13], who represents the person-oriented teaching through usage of various approaches: differentiated, individual, and subjectpersonal.

For teachers working with intellectually gifted students, person-oriented teaching is: place;

- organized training where personal development takes

- creating conditions for activity development;

- original training of teachers' due to the subjectivity of the learning process [14];

- organizing training conditions by changing the educational process;

- training where a means defines the direction and borders of the used material in professional activities;

- training, allowing one to solve problems of the training process in professional activities.

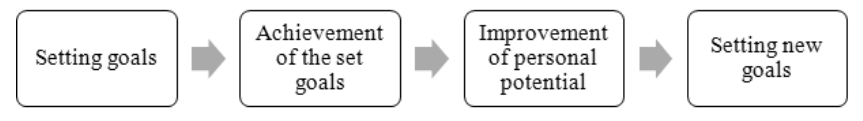

Fig. 3. The process of self-development
Training teachers to manage the development of intellectually gifted students requires great emotional and intellectual costs, mental strain, therefore they need psychological support. In this regard, let us propose the third pedagogical condition - provision teachers' psychological support in the conditions of continuing professional education in the process of the formation of their readiness to manage the development of intellectually gifted students.

The psychological support is used to strengthen teacher's self-esteem and personal self-development. It helps to be prepared for work with intellectually gifted students, to avoid mistakes in professional activity or to correct them if there are any, and to support in case of failures. Intensity of training leads to the increase of mental strain. Some teachers are subject to stress and frustration (negative mental state). Therefore, it is necessary to provide teachers with psychological support both during the courses conducted in the conditions of continuing professional education and in educational institutions. A special role in the psychological support belongs to trainings. Pedagogical trainings are necessary for the development of creative potential, development of initiative, feeling geared up for selfdevelopment, readiness to work with a certain category of students. Trainings have practical application and are used for a specific purpose:

- acquisition of knowledge;

- usage of available knowledge;

- improvement of certain skills, etc.

Training includes a variety of methods: business games, role-playing games, discussions, brainstorming, case study, facilitation, etc.

Participation of a teacher in psychological training, who is going to work or already working with intellectually gifted students, will optimize communicative skills, guide them in emerging pedagogical situations, stimulate openness and the ability to take a different attitude, improve self-esteem and activity.

After training, it is necessary to ensure the application of the gained knowledge and skills in teachers' pedagogical activities by attending seminars, workshops, coaching, participation in mentoring, etc.

The effectiveness of using the proposed pedagogical conditions was verified using a special course on preparation of teachers to manage the development of intellectually gifted students. Four groups were formed, namely: a control group (CG), which used some elements of pedagogical conditions; experimental group 1 (EG 1), using the first pedagogical conditions in preparation; experimental group 2 (EG 2), using the first and second pedagogical conditions in preparation; experimental group 3 (EG 3), using all three pedagogical conditions in preparation. Initial control showed the following results (Table 1): 
TABLE I. DISTRIBUTION OF TEACHERS BY LEVELS OF READINESS FORMATION TO MANAGE THE DEVELOPMENT OF INTELLECTUALLY GIFTED STUDENTS (INITIAL CONTROL)

\begin{tabular}{|c|c|c|c|c|c|c|c|}
\hline \multirow{2}{*}{ Group } & \multirow{2}{*}{$\begin{array}{c}\text { Number } \\
\text { of } \\
\text { people } \\
\text { in a } \\
\text { group }\end{array}$} & \multicolumn{2}{|c|}{ Leproductive } & \multicolumn{2}{|c|}{ algorithmic } & \multicolumn{2}{c|}{ creative } \\
\cline { 3 - 8 } & & Quantity & $\%$ & Quantity & $\%$ & Quantity & $\%$ \\
\hline CG & 18 & 12 & 66.7 & 4 & 22.2 & 2 & 11.1 \\
\hline EG-1 & 18 & 15 & 83.3 & 2 & 11.1 & 1 & 5.6 \\
\hline EG-2 & 19 & 14 & 73.7 & 3 & 15.8 & 2 & 10.5 \\
\hline EG-3 & 19 & 15 & 78.9 & 3 & 15.8 & 1 & 5.3 \\
\hline
\end{tabular}

To determine the level of readiness, let us propose using the reproductive, algorithmic and creative levels.

The reproductive level is characterized by unstable interest in working with intellectually gifted students, misunderstanding the social and personal importance of the pedagogical activity of this direction. Lecturers have a superficial idea of the features of this category of students, modern concepts of giftedness, and they do not master enough knowledge of developing technologies. Designing tasks is based on strictly regulated instructions; there is no independence in decision-making. They are characterized by low self-organization and self-control. A low level of activity leads to the fact that working with intellectually gifted students is situational in nature, their search initiative is not stimulated. The ability to reflect is weak.

The algorithmic level is characterized by conscious interest in working with intellectually gifted students, understanding the personal importance of this kind of activity. At the same time, their knowledge about features of this category of students, modern concepts of giftedness are not complete and deep enough. Lecturers know the developing technologies; however they prefer to work using well-proven algorithms. When designing tasks, there is an aspiration to comprehend the meaning of the studied, to establish connections, to master the ways of applying knowledge in changed conditions. However, they are characterized by a low degree of self-organization, self-control and creativity. They have a sufficient level of activity, which allows them to regularly train intellectually gifted students to participate in subject Olympiads, competitions of scientific projects. However they lack the skills to carry out productively functions of targeted orientation and stimulation of students' search initiatives. An ability to reflect is developed insufficiently, though reflexive skills are realized at a necessary level.

The creative level is characterized by understanding of the importance of working with intellectually gifted students, availability of cognitive, professional and valuable, personal motives, strong interest in this direction of pedagogical activity and ways of its implementation, satisfaction with the results obtained. The lecturers master deep knowledge about the features of this category of students, modern concepts of giftedness and use them actively in practice. When designing, tasks novelty and originality are shown. The search initiative of students is constantly stimulated during classes. The lecturers are distinguished by high self-organization, selfcontrol and creativity. A high level of activity contributes to the organization of purposeful and systematic work with intellectually gifted students and ensures their productivity. The ability to reflect is strong.

Based on the results of applying the pedagogical conditions in the training of lecturers, the following results were obtained (Table 2):

TABLE II. RESULTS OF DISTRIBUTION OF TEACHERS BY LEVELS OF READINESS FORMATION TO MANAGE THE DEVELOPMENT OF INTELLECTUALLY GIFTED STUDENTS (FINAL CONTROL)

\begin{tabular}{|c|c|c|c|c|c|c|c|}
\hline & \multirow{2}{*}{$\begin{array}{c}\text { Number } \\
\text { of } \\
\text { Group } \\
\text { people } \\
\text { in a } \\
\text { group }\end{array}$} & \multicolumn{2}{|c|}{ Leproductive } & \multicolumn{2}{|c|}{ algorithmic } & \multicolumn{2}{c|}{ creative } \\
\cline { 3 - 8 } & & Quantity & $\%$ & Quantity & $\%$ & Quantity & $\%$ \\
\hline CG & 18 & 7 & 38.9 & 9 & 50.0 & 2 & 11.1 \\
\hline EG-1 & 18 & 3 & 16.7 & 8 & 44.4 & 7 & 38.9 \\
\hline EG-2 & 19 & 1 & 5.3 & 8 & 42.1 & 10 & 52.6 \\
\hline EG-3 & 19 & 0 & 0 & 6 & 31.6 & 13 & 68.4 \\
\hline
\end{tabular}

\section{CONCLUSION}

The results of the research showed that the use of a set of pedagogical conditions can raise the lecturers' level from reproductive to creative, and increase the effectiveness of managing the process of development of intellectually gifted students.

Further research can be focused on the analysis of pedagogical conditions necessary for lecturers' preparation to manage the development of intellectually gifted students in institutions of higher education.

The results of the study can be used in organization of the teaching process in institutions of continuing professional education and giving lectures on psychology and pedagogy in educational institutions, where intellectually gifted students are taught, as well as in improvement of the psycho-pedagogical culture of general public.

\section{References}

[1] N.V., Kolodiy, "Management of the development of children's giftedness in the conditions of a specialized boarding school for gifted children," Dissertation of Candidate of science in pedagogy, Chelyabinsk, 2007, 190p.

[2] V.I., Panov, "Gifted children: identification-training-development," Pedagogy, 2001, No.4, pp.30-44.

[3] A.K., Satova, "Theoretical and methodological bases of personality development of gifted students," Dissertation abstract of Doctor of science in psychology, Almaty, 2008, 53p.

[4] G.R., Eremeeva, R.R., Bikbulatov, A.R., Baranova, "Specificity of teacher's activity in intellectually gifted students' education," Journal of Organizational Culture, Communications and Conflict, vol. 20, Special Issue2, 2016, pp. 76-81.

[5] N.V., Kuzmina, "Acmeological theory of improvement of quality of preparation of specialists of education: monograph", Moscow, 2001, $144 \mathrm{p}$. 
[6] V.A., Slastenin, "Formation of professional culture of a teacher", Moscow, 2003, 228p.

[7] Ye.N., Shiyanov, "Personality development in training," Moscow: Akadamia, 1999, 288p.

[8] Ye.V., Yakovlev, N.O. Yakovleva, "Pedagogical research: content and presentation of the results", Chelyabinsk, 2010, 317p. (in Russian).

[9] N.V., Dudyreva, "Psychological readiness of a teacher to work with gifted students," Dissertation of Candidate of science in psychology, Yaroslavl, 2013, 249p.

[10] Ye.L., Melnikova, "Psychological model of teacher preparation for work with gifted schoolchildren," Dissertation abstract of Candidate of science in psychology, Moscow, 1998, 42p.
[11] I.I., Ushatikova, "Preparing future teachers to work with gifted schoolchildren," Dissertation of Candidate of science in pedagogy, Kazan, 2006, 219p.

[12] Ye.V., Berezhnova, "Applied research in pedagogy: monograph", Volgograd: Peremena, 2003, 164p.

[13] I.S., Yakimanskaya, "Technology of person-oriented education," Moscow: Sentyabr, 2000, 176p.

[14] G.R., Eremeeva, A.R., Baranova, "Dialogization of professional communication between students and lecturers," Journal of Organizational Culture, Communications and Conflict, vol. 20, Special Issue, 2016, pp. 128-134. 